\title{
Liver-enriched transcription factors are critical for the expression of hepatocyte marker genes in mES-derived hepatocyte-lineage
} cells

\author{
Pakpoom Kheolamai*1,2 and Alan J Dickson ${ }^{1}$
}

Address: ${ }^{1}$ Faculty of Life Sciences, The University of Manchester, Manchester, M13 9PT, UK and 2Faculty of Medicine, Thammasat University, Pathumthani, 12120, Thailand

Email: Pakpoom Kheolamai* - pkheolamai@ @otmail.com; Alan J Dickson - alan.dickson@manchester.ac.uk

* Corresponding author

Published: 23 April 2009

BMC Molecular Biology 2009, 10:35 doi:10.1 186/147/-2199-10-35

This article is available from: http://www.biomedcentral.com//47/-2/99/10/35

(c) 2009 Kheolamai and Dickson; licensee BioMed Central Ltd.

This is an Open Access article distributed under the terms of the Creative Commons Attribution License (http://creativecommons.org/licenses/by/2.0), which permits unrestricted use, distribution, and reproduction in any medium, provided the original work is properly cited.
Received: 3 October 2008

Accepted: 23 April 2009

\begin{abstract}
Background: Induction of stem cell differentiation toward functional hepatocytes is hampered by lack of knowledge of the hepatocyte differentiation processes. The overall objective of this project is to characterize key stages in the hepatocyte differentiation process.

Results: We established a mouse embryonic stem (mES) cell culture system which exhibited changes in gene expression profiles similar to those observed in the development of endodermal and hepatocyte-lineage cells previously described in the normal mouse embryo. Transgenic mES cells were established that permitted isolation of enriched hepatocyte-lineage populations. This approach has isolated $\mathrm{mES}$-derived hepatocyte-lineage cells that express several markers of mature hepatocytes including albumin, glucose-6-phosphatase, tyrosine aminotransferase, cytochrome P450-3a, phosphoenolpyruvate carboxykinase and tryptophan 2,3-dioxygenase. In addition, our results show that the up-regulation of the expression levels of hepatocyte nuclear factor- $3 \alpha,-4 \alpha$, -6 , and CCAAT-enhancer binding protein- $\beta$ might be critical for passage into late-stage differentiation towards functional hepatocytes. These data present important steps for definition of regulatory phenomena that direct specific cell fate determination.

Conclusion: The mES cell culture system generated in this study provides a model for studying transition between stages of the hepatocyte development and has significant potential value for studying the molecular basis of hepatocyte differentiation in vitro.
\end{abstract}

\section{Background}

Liver failure is one of the major causes of morbidity and mortality worldwide [1]. The only effective treatment so far for acute and chronic liver failure is liver transplantation [2]. However, liver transplantation has several limitations, especially, the shortage of organ donors. During the last decade, hepatocyte transplantation therapy has emerged as an attractive alternative treatment for endstage liver disease [3-5]. To enhance the potential for this approach, hepatocyte transplantation therapy requires a renewable cell source of functional hepatocytes in vitro. One of the most promising potential sources of functional hepatocytes is from directed embryonic stem (ES) cell differentiation. 
At present, lack of detailed knowledge of the hepatocyte differentiation events restricts this potential. Several groups have reported that mouse embryonic stem (mES) cells can differentiate towards hepatocyte-lineage, based on the expression of several hepatocyte-lineage marker genes, but the underlying mechanisms that steer the induction of stem cell differentiation toward functional hepatocytes is poorly characterized [6-9]. Hepatocyte-lineage marker genes have been categorized into four groups, representing stages in the potential sequence of molecular events of hepatocyte differentiation. The first group are endodermal markers (expressed in endodermal cells, the precursor of all hepatocyte-lineage cells) including $\alpha$-fetoprotein (AFP) and hepatocyte nuclear factor-3 $\beta$ (HNF-3 $\beta$ ) [10]. The second group are fetal hepatocyte markers (expressed in fetal hepatocytes) including albumin $[10,11]$. The third group are perinatal hepatocyte markers (expressed in hepatocytes around the time of birth) including glucose-6-phosphatase (G6Pase) and tyrosine aminotransferase (TAT) [12]. The fourth group are postnatal (mature) hepatocyte markers (expressed in hepatocytes in the period following birth) including cytochrome P450-3a (Сур3a), phosphoenolpyruvate carboxykinase (Pepck) and tryptophan 2,3-dioxygenase (TDO) [13,14].

The expression of hepatocyte-lineage marker genes is primarily regulated at transcriptional level $[15,16]$. Promoters of hepatocyte-lineage marker genes contain combinations of DNA regulatory elements for binding liver-enriched transcription factors (LETFs) $[15,16]$. Despite the importance of LETFs in regulation of expression of hepatocyte-lineage marker genes, as yet, few studies have examined the profile and sequence of expression of LETFs in the differentiation of ES cells.

The overall aim of this study was to determine the expression of LETFs during differentiation of ES cells toward hepatocyte-lineages in vitro. Our study had two linked stages. Firstly, we developed culture conditions that enhanced differentiation towards a hepatic phenotype. Secondly, to permit a more detailed characterization of the underlying regulatory mechanisms that define mESderived hepatocyte-lineage cells, transgenic mES cell lines expressing green fluorescent protein (GFP), under the control of an albumin promoter/enhancer element were created and used to purify hepatocyte-lineage cells by fluorescent-activated cell sorting (FACS). The pattern of expression of hepatocyte-lineage marker and LETF genes was examined in populations of cells generated from FACS.

\section{Results HIM exhibits enhanced potential for differentiation of mES cells toward hepatocyte-lineages}

RT-PCR analysis of differentiation marker gene expression indicated that culturing of cells in hepatocyte inducing medium (HIM) supported mES cell differentiation through to postnatal stage of hepatocyte development. Populations generated from culture in non-differentiated ES medium (NDESM) without leukemia inhibitory factor (LIF) expressed endodermal marker genes (AFP and HNF$3 \beta$ ) but failed to show the expression of fetal (albumin), perinatal (G6Pase and TAT) or postnatal (Cyp3a and TDO) hepatocyte marker genes throughout the time course of culture (up to day 23) (Figure 1A). In contrast, mES cell populations generated from culture in HIM showed expression of all hepatocyte-lineage marker gene examined including postnatal hepatocyte markers (Figure 1B). In addition, the hepatocyte marker genes in HIM culture were expressed in an order (endodermal, fetal, perinatal, postnatal) similar to that observed in the development of the normal mouse embryo $[6,17]$. How-

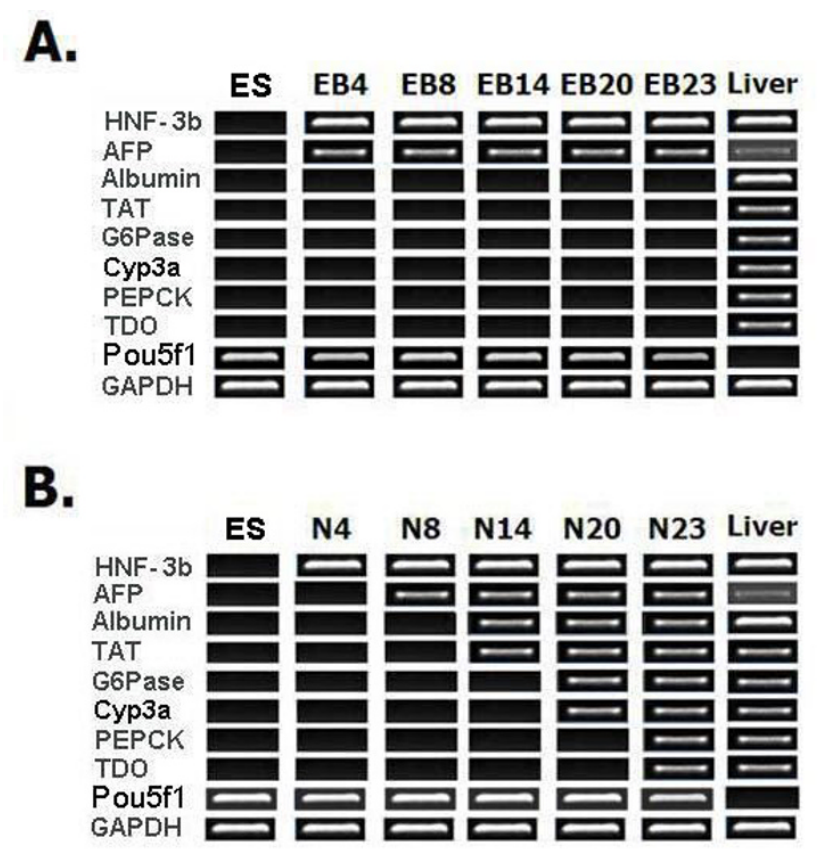

Figure I

RT-PCR analysis for hepatocyte-lineage marker genes of $\mathrm{mES}$ cell populations generated from NDESM and HIM cultures. The figure shows agarose gel electrophoresis of RT-PCR analysis for HNF-3b, AFP, Albumin, TAT, G6Pase, Cyp3a, Pepck and TDO gene expression from $m E S$ cell population generated from NDESM culture (A) or HIM culture (B) over periods of culture [HNF-3b = hepatocyte nuclear factor-3 3 , AFP $=\alpha$-fetoprotein, ALB = albumin, Сyp3a = cytochrome P450-3a, G6Pase = glucose-6phosphatase, Pepck = phosphoenolpyruvate carboxykinase, Pou5fI = POU domain class5 transcription factor I, TAT = tyrosine aminotransferase, TDO = tryptophan 2,3-dioxygenase, Liver $=$ intact mouse liver. $\mathrm{EB}=\mathrm{mES}$ cell populations generated from NDESM culture, ES = non-differentiated $m E S$ cells, $\mathrm{N}=\mathrm{mES}$ cell populations generated from HIM culture, Number indicate days in culture (as described in materials \& methods)]. 
ever, the expression of Pou5f1 was observed throughout the culture period implying that some non-differentiated mES cells were present even at the end of the culture (Figure 1).

\section{Flow cytometry fractionation of hepatocyte-lineage cells from differentiated $m E S$ cell populations}

Although culture in HIM enhanced the derivation of cells of hepatocyte-lineage, it was clear that mES cell populations generated from this culture condition contained mixed cell types. Most mES cells (under light microscopy) exhibited circular-shaped cell morphology with a diameter about $10 \mu \mathrm{m}$ but some (a minority) exhibited epithelial-like morphology (polygonal-shaped by microscopy, diameter about $15 \mu \mathrm{m}$, data not shown). The observed heterogeneity limited the interpretation of changes in gene expression in terms of differentiation toward hepatocyte-lineage. Consequently, linked to HIM culture, we isolated hepatocyte-lineage cells from the mixed population by fluorescence with EGFP expressed from a reporter construct under the control of a hepatocyte-specific (albumin) promoter/enhancer element.

After mES cell transfection, 66 clonal transfectants (pALBEGFP/ES) were obtained and four randomly selected pALB-EGFP/ES cell lines were cultured in HIM and the percentages of GFP-expressing cells (considered here to be hepatocyte-lineage cells) were determined by flow cytometry. One cell line, A.9, expressed a higher percentage of GFP-expressing cells than the others upon differentiation and this cell line was selected for a more detail analysis of mES cell differentiation using FACS. GFP-expressing cells were purified from the A.9 populations, after 21 days (A.9.2+) and 23 days (A.9.3+) of culture by FACS and GFP-negative cells (considered here to be non-hepatocytelineage cells) were also isolated at each stage of culture (A.9.2- and A.9.3-, respectively) (Figure 2B-C). The percentage of GFP-expressing cells was increased from 17.81 $\pm 3.4 \%$ at culture day 21 to $23.74 \pm 2.8 \%$ at culture day 23 (Figure 2B-C). The sorted GFP-expressing cells homogeneously exhibited epithelial-like morphology (polygonalshaped with refractive cell border, diameter about $15 \mu \mathrm{m}$ ) (Figure 2D). Unsorted cells from cultured cell line A.9 were harvested at 23 days of culture (N23) as a further comparator. RT-PCR indicated that N23 expressed all the hepatocyte-lineage marker genes including HNF-3 $\beta$, AFP, albumin, TAT, G6Pase, Cyp3a, Pepck and TDO (Figure 3). All hepatocyte-lineage marker genes detected in N23 were also detected in purified GFP-expressing cells (A.9.2+ and A.9.3+). In addition, the expression of Pou5f1 was absent in both A.9.2+ and A.9.3+ indicating that the contaminated non-differentiated mES cells were separated from the populations after FACS (Figure 3). The A.9.3- population expressed several hepatocyte-lineage marker genes (HNF-3 $\beta$, AFP, albumin, TAT) but crucially did not express perinatal or postnatal marker genes (G6Pase, Pepck, Cyp3a and TDO) (Figure 3). These data indicate that the A.9 cell line cultured in HIM could generate cells with the genetic characteristics of mature hepatocytes, which by sorting allow for subsequent definition of the relationships between cell line development and transcriptional regulatory events.

As a further step towards understanding regulatory events linked to mature hepatocyte differentiation processes, the expression of cytochrome P450-3a (Суp3a) and glucose6-phosphatase (G6Pase) was measured in A.9.2+ and A9.3+ cells by quantitative real-time PCR (qRT-PCR). Expression of Cyp3a and G6Pase increased from 21 to 23 days of culture in the GFP-expressing populations towards the level found in intact mouse liver (about 2.4 and $15.4 \%$ of the intact liver value, respectively) (Figure 4 ).

\section{Expression of liver-enriched transcription factors during $m$ ES cell differentiation}

Having defined a method for enhancement of differentiation towards hepatocyte-lineage (culture in HIM) and a means to enrich hepatocyte-lineage cells, we sought to examine how control of differentiation towards hepatocyte lineage was related to the pattern of expression of the network of LETFs. To this end we determined expression of 7 LETFs at mRNA level throughout mES culture in HIM and in populations separated on the basis of PALB-EGFP expression (Figure 5)

Expression of HNF-1 $\beta$ in mES cell populations was greatest (about $69 \%$ of intact mouse liver value) at day 4 of culture and remained constant over a further 10 days before decreasing (to about $8 \%$ of intact mouse liver value) (Figure $5 \mathrm{~A}$ ). The expression of HNF-3 $\beta$ increased over the first 10 days of culture and reached its highest value (about $48 \%$ of intact mouse liver value) at day 14 before decreasing (to about $8 \%$ of intact mouse liver value) (Figure 5B). HNF- $3 \alpha$ and C/EBP- $\beta$ exhibited a pattern of expression that was similar to that of HNF-3 $\beta$, increasing over the first 8 days of culture to reach their highest values (about $8 \%$ and $21 \%$ of intact mouse liver value, respectively) at day 8 before decreasing (to about $2 \%$ and $4 \%$ of intact mouse liver value, respectively) (Figures 5C-D).

Although the expression of HNF-4 $\alpha$ and HNF-6 also increased over the first 8 days of culture, to reach its greatest expression at that time (about $1 \%$ and $2 \%$ of intact mouse liver value, respectively) the expression of these two transcription factors remained unchanged from that point until the end of culture (Figures 5E-F). In contrast to all other LETF genes examined, C/EBP- $\alpha$ mRNA could not be detected at any stage of culture (despite ready detection in samples from intact mouse liver, data not shown). 


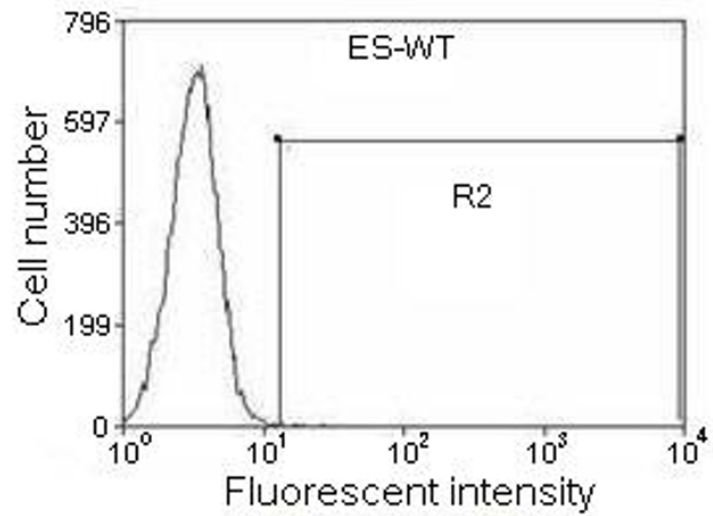

mES-wild type (without vector transfection) $R 2=0.18 \pm 0.04 \%$ of total population

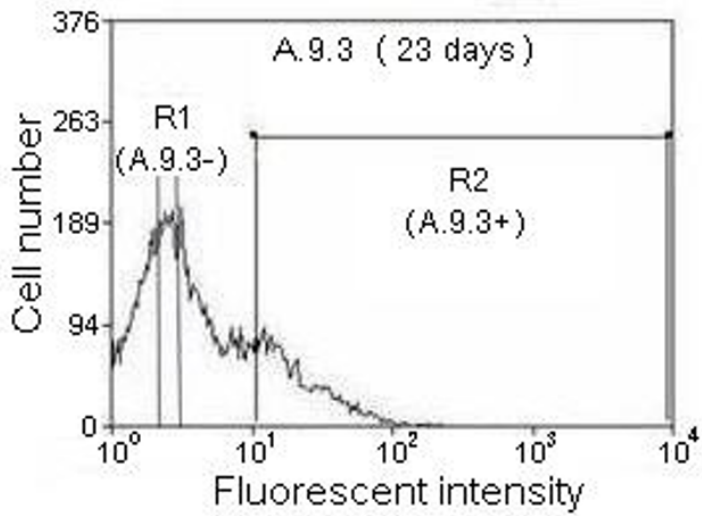

Cultured A.9 population at culture day 23 $R 2=23.74 \pm 2.8 \%$ of total population


Cultured A.9 population at culture day 21
$R 2=17.81 \pm 3.4 \%$ of total population



Morphology of GFP+ cells

Figure 2

Fluorescent-activated cell sorting (FACS) of GFP-expressing cells and GFP-negative cells from cultured A.9 populations. The figure shows the percentage of GFP-expressing cells in cultured A.9 populations at culture day 2 I (B) and day $23(\mathrm{C})$. Non-transfected mES cell population (ES-WT) serve as a negative control to determine the intrinsic fluorescent intensity of the cultured mES cell populations and to define positive area R2 (A). GFP-expressing cells from R2 regions and GFP-negative cells from $R I$ regions of cultured A.9 populations (B-C) were sorted using a Becton Dickinson FACstar flow cytometer and CellQuest ${ }^{\circledR}$ software. Data are presented as means \pm SEM. (D) show the morphology of sorted GFP-expressing cells [A.9.2+ = GFP-expressing cells purified from cultured A.9 population at culture day 21, A.9.2- = GFP-negative cells purified from cultured A.9 population at culture day 21 , A.9.3+ = GFP-expressing cells purified from cultured A.9 population at culture day $23, \mathrm{~A} .9 .3-=$ GFP-negative cells purified from cultured A.9 population at culture day $23, \mathrm{RI}=\mathrm{GFP}$-negative cells, $\mathrm{R} 2=$ GFP-expressing cells].

GFP-expressing cell populations were isolated from A.9 cells cultured in HIM for 21 (A.9.2+) and 23 (A.9.3+) days. It was notable that the expression of all LETFs examined increased progressively from 21 to 23 days of culture for GFP-expressing populations (Figures 5A-F). In particular, the expression of HNF- $3 \alpha$ and C/EBP- $\beta$ in the A.9.3+ population reached values similar to those observed for intact mouse liver (Figures 5C-D). In contrast to HNF-3 $\alpha$ and C/EBP- $\beta$, the expression of HNF- $4 \alpha$ and HNF- 6 in the A.9.3+ population was still much lower than that of intact mouse liver (about $4 \%$ of intact mouse liver value, in each 


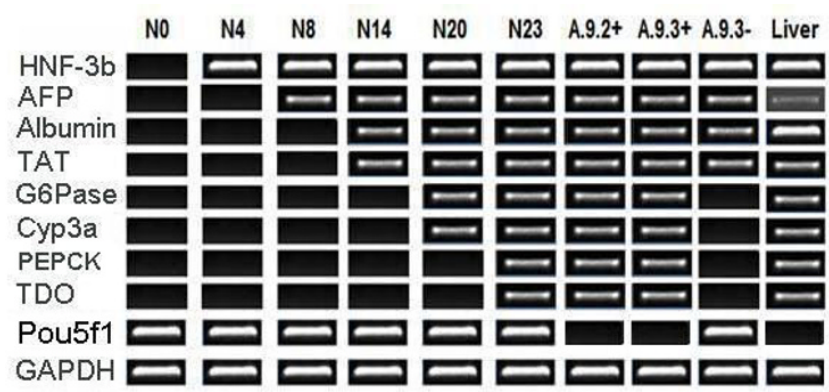

Figure 3

RT-PCR analysis for hepatocyte-lineage marker genes in PALB-EGFP/ES cell line 9 (A.9) cultures. The figure shows agarose gel electrophoresis of RT-PCR analysis for HNF-3 $\beta$, AFP, Albumin, TAT, G6Pase, Cyp3a, TDO and Pepck gene expression in PALB-EGFP/ES cell line 9 (A.9) cultured in HIM [N = mES cell populations generated from HIM culture, Number indicate days in culture (as described in materials \& methods), A.9.2+ = GFP-expressing cells purified from cultured $\mathrm{A} .9$ population at culture day 21 , A.9.3+= GFP-expressing cells purified from cultured A. 9 population at culture day 23, A.9.3- = GFP-negative cells purified from cultured A.9 population at culture day $23, \mathrm{HNF}-3 \mathrm{~b}=$ hepatocyte nuclear factor-3 $\beta$, AFP $=\alpha$-fetoprotein, Сур $3 \mathrm{a}=$ cytochrome P450-3a, G6Pase = glucose-6-phosphatase, Pepck = phosphoenolpyruvate carboxykinase, Pou $5 \mathrm{fl}=\mathrm{POU}$ domain class 5 transcription factor I, TAT = tyrosine aminotransferase, TDO = tryptophan 2,3-dioxygenase, Liver $=$ intact mouse liver]. case) (Figures 5E-F). Again, C/EBP- $\alpha$ mRNA expression was undetectable (data not shown).

For GFP-negative cell populations isolated after 21 and 23 days of culture (A.9.2- and A.9.3-), the expression of HNF$1 \beta$, HNF-3 $\beta$, HNF- 6 and C/EBP- $\beta$ was similar to that of non-differentiated mES cells (NO) (Figures 5A, B, D, F) whereas the expression of HNF- $3 \alpha$ and HNF- $4 \alpha$ were similar to that of the unsorted albumin-negative cultured mES cell population (N8) (Figure 5C, E).

\section{Discussion}

The ability of ES cells to differentiate to various cells of ectoderm, mesoderm and endoderm lineages in vitro offers a promising system to study cell differentiation processes that opens the potential for cell replacement therapy. In this study, we categorized the hepatocyte-lineage marker genes into four groups (endodermal, fetal hepatocyte, perinatal hepatocyte and postnatal hepatocyte) according to the expression pattern during the development of mouse liver $[10-14,18,19]$ to facilitate the identification of the corresponding developmental state of the differentiated mES cells. We demonstrated that even though the differentiated EBs can generate endodermal cells (precursor of all hepatocyte-lineages), these mES-derived endodermal cells cannot proceed past a specific "check point" to generate hepatocyte-like cells (which express fetal, perinatal and postnatal hepatocyte
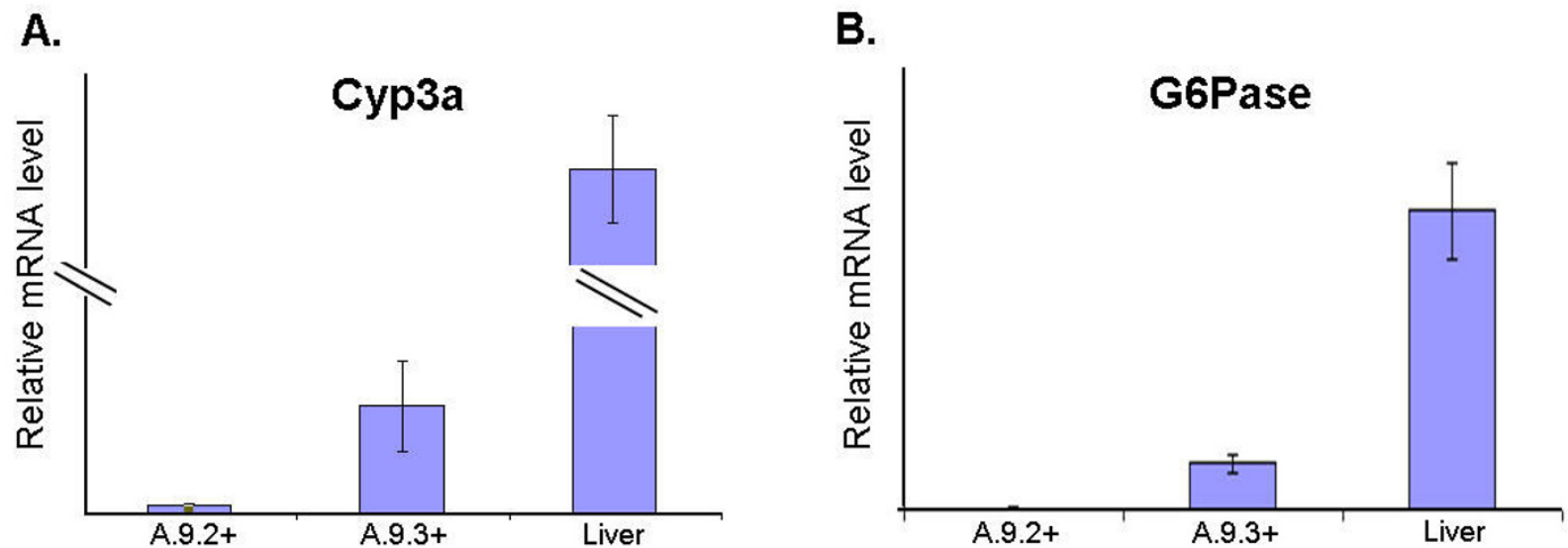

Figure 4

The expression of Cyp3a and G6Pase genes in A.9.2+ and A.9.3+ populations. The figure shows the expression level of Cyp3a (A) and G6Pase (B) genes in A.9.2+, A.9.3+ populations. Data are presented as means \pm SEM of three independent experiments. (A.9.2+ = GFP-expressing cells purified from cultured A.9 population at culture day 21 , A.9.3+ = GFP-expressing cells purified from cultured A.9 population at culture day 23, Сyp3a = cytochrome P450-3a, G6Pase = glucose-6-phosphatase, Liver $=$ intact mouse liver). [*P $<0.05$ vs. A.9.2+]. 

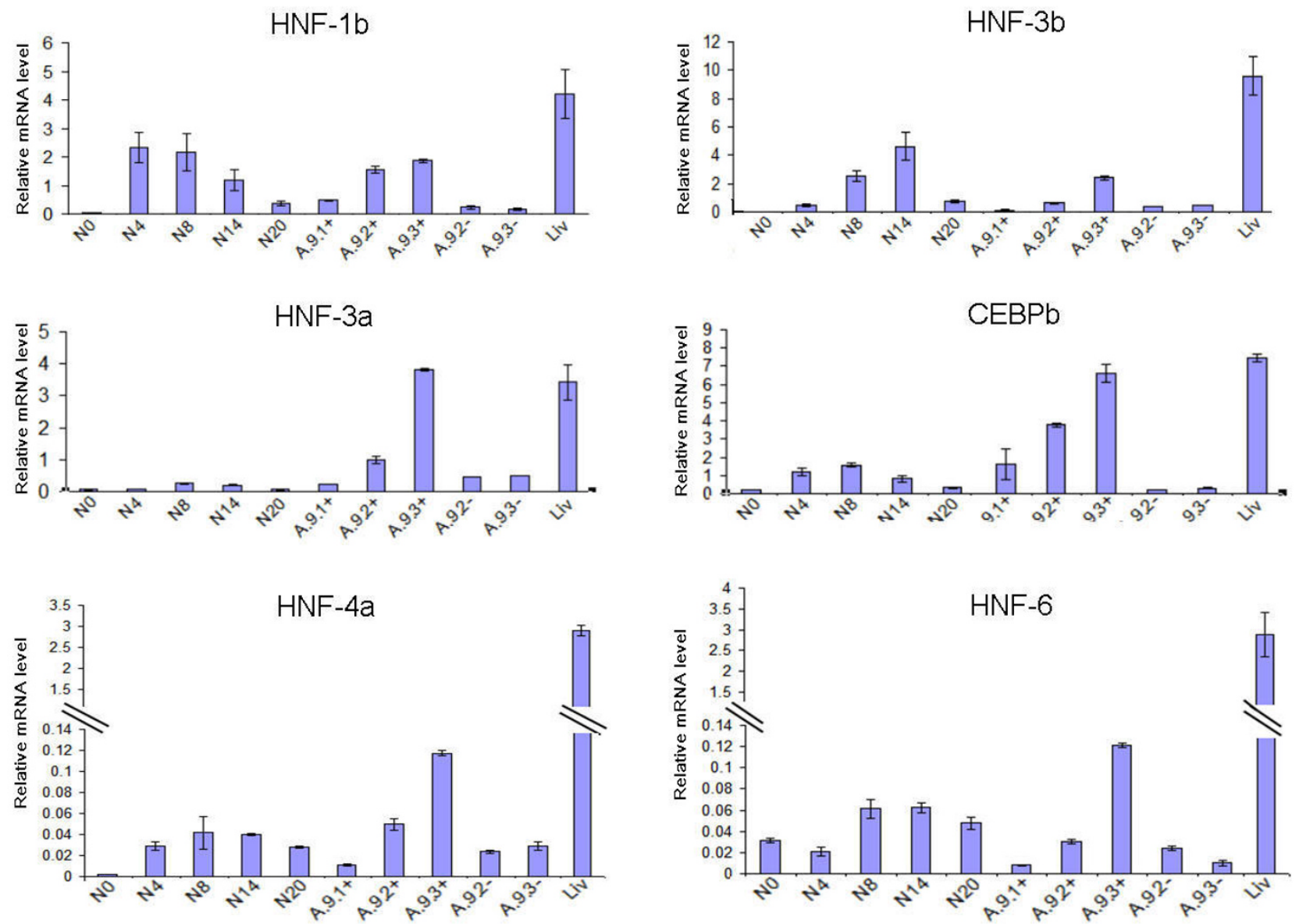

\section{Figure 5}

The expression of liver-enriched transcription factor genes in pALB-EGFP/ES cell line 9 (A.9) cultures. The figure shows the expression levels of HNF-Ib (A); HNF-3b (B); HNF-3a (C); C/EBP-b (D); HNF-4a (E) and HNF-6 (F) genes in PALB-EGFP/ES cell line 9 (A.9) cultured in HIM. Data are presented as means \pm SEM of three independent experiments (A.9.2+ = GFP-expressing cells purified from cultured A.9 population at culture day 21 , A.9.3+ = GFP-expressing cells purified from cultured A.9 population at culture day 23, A.9.3- = GFP-negative cells purified from cultured A.9 population at culture day 23, HNF-Ib, HNF-3b, HNF-3a, HNF-4a, HNF-6 = hepatocyte nuclear factor-I $\beta,-3 \beta,-3 \alpha,-4 \alpha$ and 6 , respectively; C/EBP-b = CCAAT-enhancer binding protein $\beta$, Liver $=$ intact mouse liver). [ ${ }^{*} \mathrm{P}<0.05$ vs. $\mathrm{N}$ populations].

marker genes) without the supplementation of some undetermined critical factors (Figure 6).

Several previously published papers have reported that mES cell-derived EBs expressed ALB and TAT genes, when cultured in same medium as our control condition, NDESM $[9,20,21]$. There are several potential reasons that would explain the apparent discrepancy. Firstly, the mES cell lines used in this study is different from those used in previous publications. It is well known that different mES cell lines have varied differentiation capacity even though cultured in the same conditions [22-24]. Secondly, unlike previous studies, we did not use the "hanging drop method" for generating EBs and this is an important factor which might contribute to the differences in the experimental results.

This is the first report, to our knowledge, to demonstrate that a relatively simple medium, supplemented with insulin and dexamethasone and no other growth factors, can support induction of cultured mES cells towards endodermal and hepatocyte-lineage cells in a pattern similar to that of mouse embryos [6,17] (Figure 6). Other workers have reported a need to make sequential additions of several growth factors to mimic the expression profile of hepatocyte-lineage markers in cultured mES cells popula- 




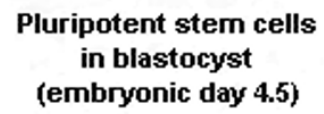

Pluripotent stem cells in blastocyst (embryonic day 4.5)

$\begin{gathered}\text { Definitive } \\ \text { endoderm }\end{gathered}$
(embryonic day 7 )
HNF-3b
AFP

Fetal hepatocytes

(embryonic day 12)

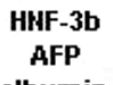

Perinatal
hepatocytes
(embryonic day 18)
HHF-3b
AFP
albumin
G6Pase

TAT

\author{
Postnatal (mature) \\ hepatocytes \\ (period following birth) \\ HNF-3b \\ AFP (low) \\ albumin \\ G6Pase \\ TAT \\ PEPCK \\ TDO \\ Cyp3a
}

Figure 6

Progression of cultured mES cells towards hepatocyte-lineages. The figure shows the progression of $\mathrm{mES}$ cells in NDESM and HIM cultures along the hepatocyte-lineages. [AFP = $\alpha$-fetoprotein, HNF-Ib, HNF-3b, HNF-3a, HNF-4a, HNF-6 = hepatocyte nuclear factor-I $\beta,-3 \beta,-3 \alpha,-4 \alpha$ and 6 , respectively; C/EBP-a, C/EBP-b $=$ CCAAT-enhancer binding protein- $\alpha$, $-\beta$, respectively; TAT $=$ tyrosine aminotransferase, Сyp3a $=$ cytochrome $\mathrm{P} 450-3 \mathrm{a}$, Pepck $=$ phosphoenolpyruvate carboxykinase, TDO = tryptophan 2,3-dioxygenase, $($ low $)=$ the expression level is low $]$.

tions but in our system this was unnecessary [6,21,25-27]. However, the percentage of albumin-expressing cells generated from HIM culture was still lower than those reported using the sequential addition of growth factors. This implies that the sequential addition of growth factors may improve the differentiation efficiency even through they are not critical for the induction of the expression of those hepatocyte-lineage genes.

It also appeared that albumin-expressing cells were also detected in GFP-negative cell populations (A.9.2- and A.9.3-) as determined by RT-PCR. This might arise through two reasons. Firstly, the albumin promoter/ enhancer region used in this study (Alb-p/e) contained only parts of the whole physiological albumin promoter. Thus, it is possible that the GFP-negative, albuminexpressing cells may produce albumin-mRNA under control of the albumin promoter regions which are located outside Alb-p/e. Secondly, it is also possible that the transfected Alb-p/e might be inactivated in some albuminexpressing A.9 cells. Such events can account for the lack of GFP-expression in albumin-expressing cells.
We have shown that up-regulation of the expression of HNF-3 $\alpha$, HNF- $4 \alpha$, HNF-6, and C/EBP- $\beta$ was specific to the hepatocyte-lineage cells in the heterogeneous cultured mES cell populations (Figure 5C-F). By implication, this suggests that these transcription factors might be required for the initiation of cell progression towards full expression of hepatocyte-lineage marker genes in mES-derived hepatocyte-like cells. In contrast, the expression of HNF$1 \beta$ and HNF-3 $\beta$ in the mES-derived hepatocyte-lineage cells (which expressed fetal, perinatal and postnatal hepatocyte markers) was not significantly different from that of albumin-negative cell populations (N4, N8, which expressed only endodermal marker genes). These data suggest that although HNF- $1 \beta$ and HNF-3 $\beta$ are required for expression of endodermal marker genes (AFP) they might not be required for the expression of fetal, perinatal and postnatal hepatocyte marker genes (albumin, TAT, G6Pase, Cyp3a, Pepck and TDO) (Figure 6).

Others have reported that expression of HNF-1 $\beta$ and HNF-3 $\beta$ was increased when definitive endoderm (the precursor of all hepatocyte lineage cells) was generated 
Table I: Target genes, primer sequences, product sizes and primer-specific annealing temperatures (AT) used for PCR

\begin{tabular}{|c|c|c|c|}
\hline Target genes & Sequences of primer $\left(5^{\prime}-3^{\prime}\right)$ & Product sizes $(\mathrm{kB})$ & AT $\left({ }^{\circ} \mathrm{C}\right)$ \\
\hline \multicolumn{4}{|c|}{ AFP (NM 007423.3) } \\
\hline Forward & cactgctgcaactcttcgta & 300 & 55 \\
\hline Reverse & ctttggaccctcttctgtga & & \\
\hline \multicolumn{4}{|c|}{ Albumin (NM_009654.I) } \\
\hline Forward & tgaactggctgactgctgtg & 718 & 55 \\
\hline Reverse & catccttggcctcagcatag & & \\
\hline \multicolumn{4}{|c|}{ HNF-3 $\beta$ (NM_0I0446.I) } \\
\hline Forward & actggagcagctactacg & 169 & 55 \\
\hline Reverse & cccacataggatgacatg & & \\
\hline \multicolumn{4}{|c|}{ Сур3а (NM_0078|8.2) } \\
\hline Forward & tacagcatggatgtgatca & 380 & 55 \\
\hline Reverse & tcatacccagcaaaaataaa & & \\
\hline \multicolumn{4}{|c|}{ G6Pase (NM_00806I.2) } \\
\hline Forward & caggactggttcatcctt & 210 & 55 \\
\hline Reverse & gttgctgtagtagtcggt & & \\
\hline \multicolumn{4}{|c|}{ Pepck (NM_0I I044.I) } \\
\hline Forward & tctgccaaggtcatccagg & 290 & 60 \\
\hline Reverse & gttttggggatgggcactg & & \\
\hline \multicolumn{4}{|c|}{ TAT (NM_|462|4.I) } \\
\hline Forward & accttcaatcccatccga & 206 & 57 \\
\hline Reverse & tccogactggataggta & & \\
\hline \multicolumn{4}{|c|}{ TDO (NM_0I99|I.2) } \\
\hline Forward & agagccagcaaaggaggac & 500 & 55 \\
\hline Reverse & ctgtctgctcctgctctgat & & \\
\hline \multicolumn{4}{|c|}{ Pou5fI (NM_0I3633.2) } \\
\hline Forward & ggcgttctctttggaaaggtgttc & 313 & 55 \\
\hline Reverse & ctcgaaccacatccttctct & & \\
\hline
\end{tabular}

Abbreviation: HNF-3b = hepatocyte nuclear factor-3 $\beta$, AFP = $\alpha$-fetoprotein, Cyp3a = cytochrome P450-3a, G6Pase $=$ glucose-6-phosphatase, Pepck = phosphoenolpyruvate carboxykinase, Pou5fI = POU domain class 5 transcription factor I, TAT = tyrosine aminotransferase, TDO = tryptophan 2,3-dioxygenase, GAPDH = glyceraldehyde-3-phosphate dehydrogenase.

and then decreased (in case of HNF-1 $\beta$ ) or remained constant (in case of HNF-3 $\beta$ ) during the remainder of liver development [28].

Although expression of HNF-3 $\alpha$ and C/EBP- $\beta$ in the A.9.3+ population (which is the highest of all cultured mES cell populations generated in this study) was similar to that of intact mouse liver, the expression of HNF- $4 \alpha$ and HNF- 6 was 40 -fold less than that of intact liver. The expression of C/EBP- $\alpha$, which is considered to be involved in perinatal and postnatal stages of hepatocyte differentiation processes [16,29-31], was not detected in any cultured mES cells populations in this study. Moreover, although A.9.2+ and A.9.3+ mES-derived cells expressed all hepatocyte-lineage marker genes examined, the expression of perinatal and postnatal hepatocyte marker genes (G6Pase and Cyp3a) was much less than that of intact mouse liver (Figure 4). The lack of the significant expres- sion of "late phase" transcription factors such as C/EBP- $\alpha$ (and HNF-4 $\alpha$ and HNF-6) implies a regulatory point of key significance towards the transition to expression perinatal and postnatal hepatocyte marker genes (G6Pase and Cyp3a) in the mES-derived hepatocyte-lineage cell populations. This interpretation agrees with reports that $C / E B P$ $\alpha$-/- mice died within 8 hours after birth due to hypoglycemia caused by low expression of several glucose metabolism enzymes including G6Pase (perinatal hepatocyte marker gene) and Pepck (postnatal hepatocyte marker gene) $[30,31]$.

\section{Conclusion}

We have provided a detailed analysis of the sequential and coordinated changes in key transcription factor gene expression in an in vitro model of hepatocyte differentiation (Figure 6). These data indicate that the regulation of expression of late phase transcription factors is critical for 
optimization of differentiation of ES cells towards a full hepatocyte phenotype in vitro. However, the direct evidence for any causal relationship between specific transcription factors and the differentiation would only arise through further experiments involving over-expression and/or knockdown of specific transcription factors. Nonetheless, the system we have developed and the molecular characterization of the transcription factor (and target gene) profiles offer a critical model for direct examination of molecular determinants of hepatocyte differentiation control. That information will not only develop further understanding of cell differentiation processes but will aid researchers in examination of the potential for use of human ES cells in the generation of donor hepatocytes for cell replacement therapies.

\section{Methods}

\section{Culture of $\mathrm{mES}$ cells}

Mouse embryonic stem (mES) cells [E14, a generous gift from Dr. Christopher Ward, The University of Manchester [23]] were maintained as described previously [6]. Briefly, non-differentiated mES cells were cultured on a gelatin- coated flask [prepared by coating a tissue culture flask with $0.1 \%(\mathrm{w} / \mathrm{v})$ Type A gelatin from porcine skin (Sigma, UK)] in LIF-NDESM which is Knockout ${ }^{\mathrm{TM}}$ Dulbecco's modified Eagle's medium (Gibco, UK) supplemented with $10 \%(\mathrm{v} / \mathrm{v})$ fetal bovine serum (Cambrex, UK), 1\% (v/ v) $10 \mathrm{mM}$ non-essential amino acids solution (Cambrex, UK), 1\% (v/v) $200 \mathrm{mM}$ L-glutamine (Cambrex, UK), $0.001 \%$ (v/v) 14.3 M $\beta$-mercaptoethanol (Sigma, UK) and 1000 unit/ml leukemia inhibitory factor (LIF, Chemicon, UK). To induce differentiation, mES cells were removed from gelatin-coated flasks by incubation with $0.25 \mathrm{mg} / \mathrm{ml}$ trypsin and $0.2 \mathrm{mg} / \mathrm{ml}$ EDTA (Cambrex, UK) for $2 \mathrm{~min}$ utes, trypsinized to a single cell suspension and transferred to bacterial Petri dishes (Falcon, UK) at a concentration of $2 \times 10^{6}$ cells $/ 10 \mathrm{~cm}$ dish in NDESM without LIF and incubated at $37^{\circ} \mathrm{C}$ in $5 \% \mathrm{CO}_{2}$ incubator for 4 days. During this time embryoid bodies (EBs) formed. At this stage (which was counted as culture day 0), EBs were plated and attached to gelatin-coated flasks in non-differentiating ES medium (NDESM) or hepatocyte-inducing medium (HIM) [NDESM without LIF supplemented with $1 \times 10^{-6} \mathrm{M}$ dexamethasone (Sigma, UK), $1 \times 10^{-8} \mathrm{M}$ insulin

Table 2: Target genes, product sizes and primer sequences used for quantitative real-time PCR

\begin{tabular}{|c|c|c|}
\hline Target genes & Sequences of primer $\left(5^{\prime}-3^{\prime}\right)$ & Product sizes (kB) \\
\hline \multicolumn{3}{|c|}{ CEBP- $\alpha$ (NM_007678.2) } \\
\hline Forward & gctttttgcacctccaccta & 170 \\
\hline Reverse & ccacaaagcccagaaaccta & \\
\hline \multicolumn{3}{|c|}{ CEBP- $\beta$ (NM_009883.I) } \\
\hline Forward & caagctgagcgacgagtaca & 157 \\
\hline Reverse & cagctgctccaccttcttct & \\
\hline \multicolumn{3}{|c|}{ HNF-I $\beta$ (NM_009330.2) } \\
\hline Forward & gacactcctcccatcctcaa & 156 \\
\hline Reverse & ctccctctgggggatattgt & \\
\hline \multicolumn{3}{|c|}{ HNF-3 $\alpha$ (NM_008259.2) } \\
\hline Forward & cagcacaagctggacttcaa & 173 \\
\hline Reverse & agcacgggtctggaatacac & \\
\hline \multicolumn{3}{|c|}{ HNF-3 $\beta$ (NM_0I0446.I) } \\
\hline Forward & taagcgagctaaagggagca & 176 \\
\hline Reverse & agagaaggggtggttgaagg & \\
\hline \multicolumn{3}{|c|}{ HNF-4 $\alpha$ (NM_00826I.2) } \\
\hline Forward & agaggttctgtcccagcaga & 169 \\
\hline Reverse & atccagaaggagttcgcaga & \\
\hline \multicolumn{3}{|c|}{ HNF-6 (NM_008262.2) } \\
\hline Forward & ctgtgaaactcccccaggta & 179 \\
\hline Reverse & tgaaactaccgctcacgttg & \\
\hline \multicolumn{3}{|c|}{ GAPDH (NM_I99472.I) } \\
\hline Forward & acccagaagactgtggatgg & 172 \\
\hline Reverse & cacattgggggtaggaacac & \\
\hline
\end{tabular}

Abbreviation: $\mathrm{HNF}=$ hepatocyte nuclear factor, $\mathrm{C} / \mathrm{EBP}=\mathrm{CCAAT}$-enhancer binding protein, GAPDH = glyceraldehyde-3-phosphate dehydrogenase 
(Sigma, UK) and $200 \mathrm{mM}$ L-glutamine (Cambrex, UK)] and allowed to attach at $37^{\circ} \mathrm{C}$ in $5 \% \mathrm{CO}_{2}$ incubator for 2 days. The appropriate culture medium was replaced every 24 hours.

\section{pALB-EGFP Plasmid Construction}

A plasmid was constructed with a 2,335 bp fragment of the mouse albumin promoter/enhancer (incorporating a region from -8.5 to $-10.4 \mathrm{~kb}$ of the albumin enhancer fused to the $-0.3 \mathrm{~kb}$ minimal albumin promoter sequences, a generous gift from Professor Richard Palmiter, University of Washington [32], cloned into a promoterless EGFP vector, pd2EGFP-1 (BD Biosciences Clontech, UK). The resulting construct was named pALBEGFP. Establishment of pALB-EGFP stable transfectants of mES cells (pALB-EGFP/ES) was performed as described previously [27]. Briefly, $1 \times 10^{7}$ non-differentiated mES cells (maintained in LIF-NDESM) were transfected with pALB-EGFP plasmid using electroporation. After electroporation and selection, pALB-EGFP-transfected mES clones were harvested and screened using genomic PCR with EGFP-specific primers. The resultant pALB-EGFP/ES cell lines were maintained in the presence of $350 \mu \mathrm{g} / \mathrm{ml}$ G418 (Gibco, UK).

\section{Fluorescence-Activated Cell Sorting (FACS)}

pALB-EGFP/ES cells were removed from culture flasks by incubation with $0.25 \mathrm{mg} / \mathrm{ml}$ trypsin and $0.2 \mathrm{mg} / \mathrm{ml}$ EDTA (Cambrex, UK) for 2 minutes and trypsinized to single cell suspensions. Suspensions (containing 0.5-1 $\times 10^{6}$ cells) were centrifuged at 13,000 $\mathrm{g}$ for 1 minute and pellets were resuspended in $500 \mu \mathrm{l} \mathrm{FACS} \mathrm{buffer} \mathrm{(PBS} \mathrm{contain-}$ ing $2 \%(\mathrm{v} / \mathrm{v})$ fetal bovine serum and $0.002 \%(\mathrm{w} / \mathrm{v})$ sodium azide). Populations were analyzed and sorted using a Becton Dickinson FACstar flow cytometer and CellQuest ${ }^{\circledast}$ software (BD Biosciences, UK). Non-transfected mES cells (ES-WT) were negative controls of the intrinsic fluorescent intensity of the cultured mES cell populations and defined the positive area for cell sorting.

\section{Reverse transcriptase-polymerase chain reaction}

RNA was extracted from cells using TRIZOL ${ }^{\circledast}$ (Invitrogen, UK) or RNeasy ${ }^{\circledR}$ Mini Kit (Qiagen, UK) and was treated with RNase-free DNase (Sigma, UK). cDNA was synthesized from $1 \mu \mathrm{g}$ of RNA using an oligo d(T)12-18 primer (Invitrogen, UK) and M-MLV reverse transcriptase (Roche, UK). PCR was performed using Taq DNA polymerase (Roche, UK): $94^{\circ} \mathrm{C}$ for 5 minutes followed by 40 cycles of denaturation $\left(94^{\circ} \mathrm{C}, 1\right.$ minute), annealing (Table 1,1 minute), extension $\left(72^{\circ} \mathrm{C}, 2\right.$ minutes) and a final extension at $72^{\circ} \mathrm{C}$ for 10 minutes. Products were separated by electrophoresis on 1\% (w/v) agarose gels. All primers used in this study (Table 1) were designed using Primer- 3 output program (Whitehead Institute for Biomedical Research, 1998) and were checked by performing Basic
Local Alignment Search Tool (BLAST) within the nucleotide databases for mouse genome to ensure their specificity.

\section{Quantitative real-time PCR (qRT-PCR)}

MJ-white 96 well plates (Bio-Rad, UK) were used for qRTPCR reactions. Each well contained 1-2 $\mu \mathrm{l}$ of cDNA, $5 \mu \mathrm{l}$ $1.2 \mu \mathrm{M}$ appropriate forward and reverse primer mix and $10 \mu \mathrm{l}$ DyNAmo $^{\mathrm{TM}}$ SYBR $^{\circledast}$ Green reaction mix (FINNZYME, Finland). The plate was sealed with Microseal 'B' clear adhesive film (Bio-Rad, UK) to prevent the evaporation of reactant. PCR was performed using an Opticon Monitor qRT-PCR thermal cycler (Bio-Rad, UK): $95^{\circ} \mathrm{C}$ initial denaturation for 10 minutes followed by 40 cycles of denaturation $\left(94^{\circ} \mathrm{C}, 10\right.$ seconds), annealing $\left(60^{\circ} \mathrm{C}, 20\right.$ seconds), extension $\left(72^{\circ} \mathrm{C}, 20\right.$ seconds) followed by denaturation $\left(76^{\circ} \mathrm{C}, 1\right.$ second). The quantity of a target gene was calculated by normalization with glyceraldehyde-3-phosphate dehydrogenase (GAPDH), using the following formula: normalized target gene quantity $=2^{\wedge}\{-[\mathrm{C}(\mathrm{T})$ target gene/ $\mathrm{C}(\mathrm{T}) \mathrm{GAPDH}$ gene] $\}$. The ' $\mathrm{C}(\mathrm{T})^{\prime}$ value was the number of reaction cycles required for the target gene to enter logarithmic amplification. For quantification, a standard curve for each gene was calculated from 3 dilutions of the cDNA template by plotting the log value of the starting concentration versus the threshold value. Primers are specified in Table 2.

\section{Statistical analysis}

Data are presented as means \pm standard error of the mean (SEM) for the number of individual cell preparations identified. In some cases one measurement in each experiment was set at $100 \%$ as indicated in the text. All other values were calculated relative to this. The paired Student's t-test was used to assess the significance of differences between observed data. $\mathrm{P}<0.05$ was considered to be statistically significant.

\section{Abbreviations}

mES: Mouse embryonic stem cell; AFP: $\alpha$-fetoprotein; HNF: hepatocyte nuclear factor; C/EBP: CCAAT-enhancer binding protein; G6Pase: Glucose-6-phosphatase; TAT: tyrosine aminotransferase; Cyp3a: cytochrome P450-3a; Pepck: phosphoenolpyruvate carboxykinase; Pou5f1: POU domain class5 transcription factor 1; TDO: tryptophan 2,3-dioxygenase; LETFs: liver-enriched transcription factors; GFP: green fluorescent protein; FACS: fluorescent-activated cell sorting; HIM: hepatocyte inducing medium; NDESM: non-differentiated ES medium; LIF: leukemia inhibitory factor; EBs: embryoid bodies; pALB-EGFP/ES: pALB-EGFP-transfected mES cell line; ESWT: Non-transfected mES cells; qRT-PCR: Quantitative real time PCR; GAPDH: Glyceraldehyde-3-phosphate dehydrogenase; SEM: standard error of the mean. 


\section{Authors' contributions}

PK carried out the experiments, performed data analysis and participated in the sequence alignment and drafted the manuscript. AJD designed and supervised the study and helped to draft the manuscript. All authors read and approved the final manuscript.

\section{Acknowledgements}

We thank Dr. Christopher Ward (The University of Manchester) for providing us $\mathrm{mES}$ cell lines, Professor Richard Palmiter (University of Washington) for providing us mouse albumin promoter/enhancer DNA fragment and Mike Jackson (The University of Manchester) for helping us in FACS. This study was supported by grant from Royal Thai Government.

\section{References}

I. Bellentani S, Tiribelli C: The spectrum of liver disease in the general population: lesson from the Dionysos study. J Hepatol 200I, 35(4):53I-537.

2. Neuberger J: Liver transplantation. J Hepatol 2000, 32(I Suppl): 198-207.

3. Ambrosino G, Varotto S, Strom SC, Guariso G, Franchin E, Miotto D Caenazzo L, Basso S, Carraro P, Valente ML, et al.: Isolated hepatocyte transplantation for Crigler-Najjar syndrome type I. Cell Transplant 2005, I4(2-3): I5I-I57.

4. Dhawan A, Mitry RR, Hughes RD: Hepatocyte transplantation for liver-based metabolic disorders. J Inherit Metab Dis 2006 29(2-3):43I-435.

5. Elaut G, Henkens T, Papeleu P, Snykers S, Vinken M, Vanhaecke T, Rogiers V: Molecular mechanisms underlying the dedifferentiation process of isolated hepatocytes and their cultures. Current Drug Metabolism 2006, 7(6):629-660.

6. Hamazaki T, liboshi Y, Oka M, Papst PJ, Meacham AM, Zon LI, Terada $\mathrm{N}$ : Hepatic maturation in differentiating embryonic stem cells in vitro. FEBS Lett 200I, 497(1):15-19.

7. Kania G, Blyszczuk P, Jochheim A, Ott M, Wobus AM: Generation of glycogen- and albumin-producing hepatocyte-like cells from embryonic stem cells. Biol Chem 2004, 385(1 0):943-953.

8. Soto-Gutierrez A, Kobayashi N, Rivas-Carrillo JD, Navarro-Alvarez $\mathrm{N}$, Zhao DB, Okitsu T, Noguchi H, Basma H, Tabata Y, Chen Y, et al.: Reversal of mouse hepatic failure using an implanted liverassist device containing ES cell-derived hepatocytes. Nature Biotechnology 2007, 25(2):254-254.

9. Yamada T, Yoshikawa M, Kanda S, Kato Y, Nakajima Y, Ishizaka S, Tsunoda $Y$ : In vitro differentiation of embryonic stem cells into hepatocyte-like cells identified by cellular uptake of indocyanine green. Stem Cells 2002, 20(2): I 46-I54.

10. Zaret KS: Regulatory phases of early liver development: paradigms of organogenesis. Nat Rev Genet 2002, 3(7):499-5 I2.

11. Tilghman SM, Belayew A: Transcriptional Control of the Murine Albumin Alpha-Fetoprotein Locus During Development. Proceedings of the National Academy of Sciences of the United States of America-Biological Sciences 1982, 79( I 7):5254-5257.

12. Haber BA, Chin S, Chuang E, Buikhuisen W, Naji A, Taub R: HighLevels of Glucose-6-Phosphatase Gene and Protein Expression Reflect an Adaptive Response in Proliferating Liver and Diabetes. Journal of Clinical Investigation 1995, 95(2):832-84I.

13. Nagao M, Nakamura T, Ichihara A: Developmental Control of Gene-Expression of Tryptophan 2,3-Dioxygenase in Neonatal Rat-Liver. Biochimica Et Biophysica Acta 1986, 867(4): I79-186.

14. Noda C. Fukushima C. Fujiwara T, Matsuda K, Kobune Y, Ichihara A: Developmental Regulation of Rat Serine Dehydratase GeneExpression - Evidence for the Presence of a Repressor in Fetal Hepatocytes. Biochimica Et Biophysica Acta-Gene Structure and Expression 1994, I 217(2): 163-173.

15. Schrem H, Klempnauer J, Borlak J: Liver-enriched transcription factors in liver function and development. Part I: The hepatocyte nuclear factor network and liver-specific gene expression. Pharmacological Reviews 2002, 54(I):129-I58.

16. Schrem H, Klempnauer J, Borlak J: Liver-enriched transcription factors in liver function and development. Part II: the $C$ EBPs and D site-binding protein in cell cycle control, carcinogenesis, circadian gene regulation, liver regeneration, apop- tosis, and liver-specific gene regulation. Pharmacological Reviews 2004, 56(2):29I-330.

17. Kamiya A, Gonzalez FJ, Nakauchi H: Identification and differentiation of hepatic stem cells during liver development. Front Biosci 2006, I I:I302-13 I0.

18. Shiojiri N, Lemire JM, Fausto N: Cell lineages and oval cell progenitors in rat liver development. Cancer Res 1991 , 5 I (I0):26II-2620

19. Greengard O: The developmental formation of enzymes in rat liver. New York: Academic Press; 1970.

20. Miyashita H, Suzuki A, Fukao K, Nakauchi H, Taniguchi H: Evidence for hepatocyte differentiation from embryonic stem cells in vitro. Cell Transplant 2002, I I(5):429-434.

21. Chinzei R, Tanaka Y, Shimizu-Saito K, Hara Y, Kakinuma S, Watanabe M, Teramoto K, Arii S, Takase K, Sato C, et al.: Embryoid-body cells derived from a mouse embryonic stem cell line show differentiation into functional hepatocytes. Hepatology 2002 , 36(I):22-29.

22. Lauss M, Stary M, Tischler J, Egger G, Puz S, Bader-Allmer A, Seiser C, Weitzer G: Single inner cell masses yield embryonic stem cell lines differing in lifr expression and their developmental potential. Biochem Biophys Res Commun 2005, 33 I (4): I 577 - I 586.

23. Ward CM, Barow KM, Stern PL: Significant variations in differentiation properties between independent mouse ES cell lines cultured under defined conditions. Experimental Cell Research 2004, 293(2):229-238.

24. Sharova LV, Sharov AA, Piao Y, Shaik N, Sullivan T, Stewart CL, Hogan BL, Ko MS: Global gene expression profiling reveals similarities and differences among mouse pluripotent stem cells of different origins and strains. Dev Biol 2007, 307(2):446-459.

25. Hu AB, Cai JY, Zheng QC, He XQ, Shan Y, Pan YL, Zeng GC, Hong A, Dai Y, Li LS: High-ratio differentiation of embryonic stem cells into hepatocytes in vitro. Liver Int 2004, 24(3):237-245.

26. Ishii T, Yasuchika K, Fujii H, Hoppo T, Baba S, Naito M, Machimoto T, Kamo N, Suemori $H$, Nakatsuji N, et al.: In vitro differentiation and maturation of mouse embryonic stem cells into hepatocytes. Exp Cell Res 2005, 309(I):68-77.

27. Yamamoto Y, Teratani T, Yamamoto H, Quinn G, Murata S, Ikeda R, Kinoshita K, Matsubara K, Kato T, Ochiya T: Recapitulation of in vivo gene expression during hepatic differentiation from murine embryonic stem cells. Hepatology 2005, 42(3):558-567.

28. Jochheim A, Hillemann T, Kania G, Scharf J, Attaran M, Manns MP, Wobus AM, Ott M: Quantitative gene expression profiling reveals a fetal hepatic phenotype of murine ES-derived hepatocytes. Int J Dev Biol 2004, 48(I):23-29.

29. Darlington GJ: Molecular mechanisms of liver development and differentiation. Current Opinion in Cell Biology 1999 , I I (6):678-682

30. Flodby P, Barlow C, Kylefjord H, Ahrlund-Richter L, Xanthopoulos KG: Increased hepatic cell proliferation and lung abnormalities in mice deficient in CCAAT/enhancer binding protein alpha. Journal of Biological Chemistry 1996, 27 I (40):24753-24760.

31. Wang ND, Finegold MJ, Bradley A, Ou CN, Abdelsayed SV, Wilde MD, Taylor LR, Wilson DR, Darlington GJ: Impaired Energy Homeostasis in C/Ebp-Alpha Knockout Mice. Science 1995, 269(5227): II08-IIII

32. Pinkert CA, Ornitz DM, Brinster RL, Palmiter RD: An albumin enhancer located $10 \mathrm{~kb}$ upstream functions along with its promoter to direct efficient, liver-specific expression in transgenic mice. Genes Dev 1987, I(3):268-276. 